\title{
External Genitalia Trauma Following the First Manic Episode in an Elderly Woman With Sexual Disinhibition
}

\author{
Reza Bidaki, ${ }^{1}$ Golrasteh Kholasezade, ${ }^{1,}{ }^{*}$ Mahdi Abedinzadeh, ${ }^{2}$ and Hormoz Karami ${ }^{2}$ \\ ${ }^{1}$ Department of Psychiatry, Research Center of Addiction and Behavioral Sciences, Shahid Sadoughi University of Medical Sciences, Yazd, IR Iran \\ ${ }^{2}$ Department of Urology, Shahid Sadoughi University of Medical Sciences, Yazd, IR Iran \\ "Corresponding author: Golrasteh Kholasezade, Department of Psychiatry, Research Center of Addiction and Behavioral Sciences, Shahid Sadoughi University of Medical \\ Sciences, Yazd, IR Iran. Tel: +98-3532632003, Fax: +98-3532633555, E-mail: Fa.net87@yahoo.com
}

Received 2015 July 22; Revised 2015 December 02; Accepted 2015 December 13.

\begin{abstract}
Introduction: Late onset bipolar disorder is not common. In addition, bipolar disorder with a dominancy over sexual behaviors is very rare. Hence, traumatic and vigorous sexual behavior, such as masturbation and self-mutilation, are odd and rare occurrences. Case Presentation: An elderly woman in a manic phase of bipolar disorder without a previous history of psychiatric disorders was concomitant with problematic sexual over stimulation in the context of hyper sexuality. She had traumatized her genitals and underwent surgery for their repair. Following her admission and psychopharmacologic therapy, she recovered.

Conclusions: The presentation of bipolar disorder in the elderly can be seen in sexual behaviors and self-mutilation that can lead to the need for reparative surgery. In each case with trauma to the external genitalia, psychiatric problems should be considered.
\end{abstract}

Keywords: Hypersexuality, Manic Episode, Self-Injury, Sexual Disinhibition, Masturbation

\section{Introduction}

Bipolar disorder is an important mood disorder with a peak age of onset between 20 and 40 years (1).

Less than $5 \%$ of patients are reported to experience the onset of bipolar after age 60 (late onset bipolar disorder (2). Indeed, in rare cases, it is a cause for admission to a psychiatric unit; the prognosis and treatment is similar to that of younger patients (3).

This problematic sexual dysfunction maybe more related to a perceived lack of self-control than to morality or sexual behavior (4).

In the literature, most cases reporting on selfmutilation had psychotic features. Genital injury is considered a type of vigorous self-injury behavior. Even ancient Romans viewed it as a religious practice (5), yet in some reports, it has been noted to happen in nonpsychotic patients (6), due to autocastration (7) and efforts toward crude sex change procedures, in pursuit of transsexualism (8).

Nearly $4 \%$ of all admitted psychiatric patients have experienced self-mutilation (9).

Although hypersexuality is not an uncommon symptom of mania, as noted in the literature, it has only rarely been reported in old women as a sexual problem. The case this paper highlights is one of unusual and strange sexual behavior in the context of current and first-episode mania. An interesting case of bipolar disorder in manic phase without a previous history of psychiatric disorders was concomitant with problematic and abnormal sexual behaviors in the context of hypersexuality.

\section{Case Presentation}

A 62-year-old woman was referred to the gynecology service at midnight. She had profound and severe lacerations and multiple-site trauma in the fossa navicularis, posterior fourchette, clitoris, and hymen. The trauma was a painful result of self-injury as a chaotic and high-risk behavior with an unknown sharp and penetrating device. She was experiencing redness, swelling, scrapes, and tears, with a lot of bleeding. She did not pretend any history of organic disease, psychiatric disorder, personality disorder, gender identity disorder, alcohol or substance use, or past sexual inadequacy. She had experienced an elevated mood, talkativeness, overspending, a decreased need for sleep, an increase in energy, and hypersexuality for the past eight days. She did not mention any history of sexual problems or marital discord.

Her family mentioned that the trauma was because of an accidental encounter. However, after a precise interview, it was clear that trauma was due to vigorous, disruptive and violent masturbation.

A gynecologist compressed the traumatized regions, and the patient was referred to the urology department. The primary approaches were performed and then she underwent general anesthesia in the operating room. The patient had urinary retention; so, a catheterization of the uri-

Copyright (C) 2016, Kashan University of Medical Sciences. This is an open-access article distributed under the terms of the Creative Commons Attribution-NonCommercial 4.0 International License (http://creativecommons.org/licenses/by-nc/4.0/) which permits copy and redistribute the material just in noncommercial usages, provided the original work is properly cited. 
nary tract was performed. The lumen and clitoris were repaired.

\subsection{After Surgery and a Follow-Up Consultation With a Psychia- trist}

The patient underwent a psychiatry consultation. She displayed talkativeness, hyperactivity, insomnia obsessive thoughts with sexual themes and overspending. She said that a command voice was the reason for her destructive behavior. She believed that she was an angel sent by God. The diagnosis was late onset bipolar disorder, first episode with a mania phase. The psychiatrist prescribed a 5-mg olanzapine tablet to be taken twice daily, Lithium carbonate $300 \mathrm{mg}$ TDS, chlorpromazine $100 \mathrm{mg} / \mathrm{Hs}$, and clonazepam $1 \mathrm{mg} / \mathrm{Hs}$. She underwent eight sessions of electroconvulsive therapy (ECT). Now, after 20 months she is asymptomatic. Her husband died five years ago. Her reaction to grief was normal at that time. Her brother is a bipolar patient.

The brain magnetic resonance imaging (MRI), routine lab tests and Electroencephalography(EEG) were all intact.

After the patient's admission, and psychopharmacology and eight sessions of ECT, she recovered and felt ashamed of expressing her condition. She mentioned that the genital trauma was an unintentional accident. After monthly follow-ups, she was in full remission and was taking her medications.

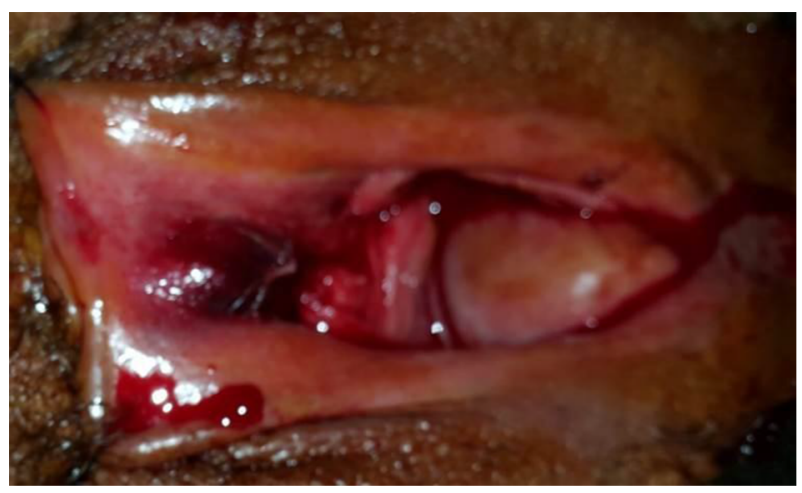

Figure 1. Laceration in the Fossa Navicularis and Posterior Forchette, Clitoris, and Hymen

\section{Discussion}

In a review of the literature, we found no case similar to this one, which involves a female. Of course, there are some cases about males.

As noted in Krauthammer and Klerman's survey, secondary mania may be characterized as late onset, if there

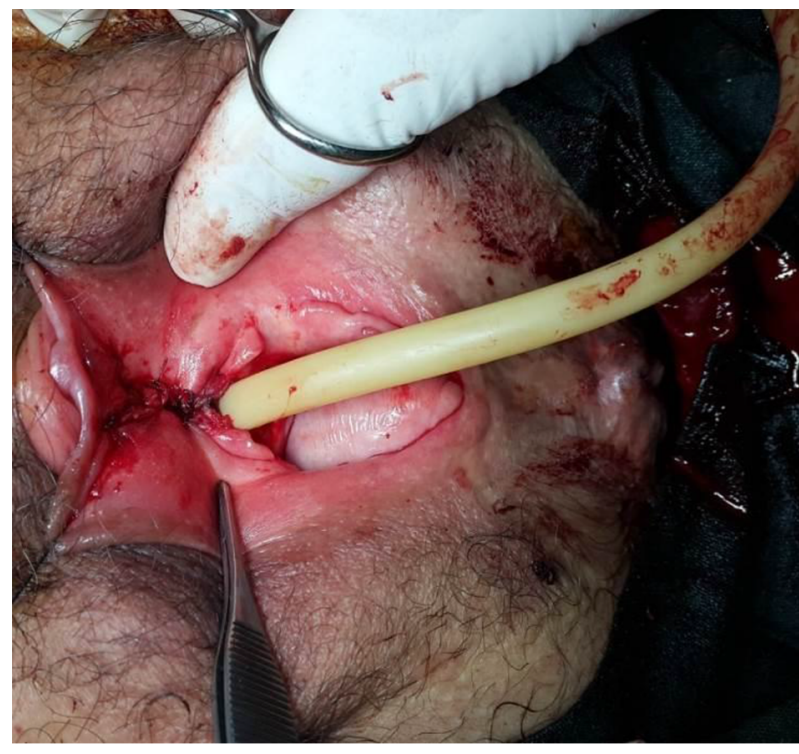

Figure 2. Catheterization and Repair of the Fossa Navicularis, Forchette, and Clitoris by a Urologist

is no family history of psychiatric disorders following the use of medications, the discovery of tumors, metabolic disorders, or seizures (10). However, our subject had a positive family history for bipolar disorder (her brother). Indeed, she and her brother were not suicidal, but her brother was not a late onset bipolar patient. It seems that hers was an unconsciousness condition with chaotic sexual boundaries. Furthermore, we investigated all probable organic causes to rule out secondary mania; however, but we did not find an organic etiology for her mania.

Although some patients may perform self-harming behaviors while following the commands of auditory hallucinations, a state called van Gogh Syndrome (11), our patient did not have this symptom.

Our patient experienced a manic episode. However, hypersexuality is highlighted in the context of this episode. Although the patient met the criteria for threatened mania, sexual behaviors are a hall mark, rather than another symptom. The patient denied this. It was not obvious that the patient had amnesia or was using an immature defense mechanism (denial) against this act.

Previous cases reported on in the literature have mostly dealt with men. This act is more prevalent among men, yet our case was a woman. She never expressed any sense of feelings of conflict, fantasy, internalized frustration, or thoughts.

Interpreting this behavior is difficult, but perhaps a psychodynamic approach or model can explain the cause of this sexual disinhibition and nonsuicidal violent behav- 
ior. The patient was not worried about her gender or sex. She was ashamed to explain what had occurred. However, her actions were an intentional trauma inflicted for the release of sexual tension. It is clear that the approach one takes when facing acts of genital self-mutilation and sexual disinhibition is a complex problem, and the evaluation and assessment of these patients calls for the integration and cooperation of the patient's surgeon, psychologist, and psychiatrist.

\subsection{Conclusion}

The uncommon nature of trauma to the genitourinary tract may be related to hypersexuality or masturbation in the context of late onset mania. In each case, when there is trauma to the external genitalia, psychiatric problems should be considered.

\section{Acknowledgments} tion.

We thank the family of the patient for their coopera-

\section{Footnote}

Authors' Contribution: Reza Bidaki: study concept and design, acquisition of data, interpretation of data, drafting the manuscript, critical revision of the manuscript, and final approval of the version to be published; Golraste Kholase Zade, Mahdi Abedinzade, and Hormoz Karami collected data and images.

\section{References}

1. Yassa R, Nair V, Nastase C, Camille Y, Belzile L. Prevalence of bipolar disorder in a psychogeriatric population. J Affect Disord. 1988;14(3):197201. [PubMed: 2968383].

2. Depp CA, Jin H, Mohamed S, Kaskow J, Moore DJ, Jeste DV. Bipolar disorder in middle-aged and elderly adults: is age of onset important?.J Nerv Ment Dis. 2004;192(11):796-9. [PubMed: 15505527].

3. Yassa R, Nair NP, Iskandar H. Late-onset bipolar disorder. Psychiatr Clin North Am. 1988;11(1):117-31. [PubMed: 3288976].

4. Carvalho J, Stulhofer A, Vieira AL, Jurin T. Hypersexuality and high sexual desire: exploring the structure of problematic sexuality.JSex Med. 2015;12(6):1356-67. doi: 10.1111/jsm.12865. [PubMed: 25808900].

5. Greilsheimer H, Groves JE. Male genital self-mutilation. Arch Gen Psychiatry. 1979;36(4):441-6. [PubMed: 426611].

6. Clark RA. Self-mutilation accompanying religious delusions: a case report and review. J Clin Psychiatry. 1981;42(6):243-5. [PubMed: 7240105].

7. Ames D. Autocastration and biblical delusions in schizophrenia. $\mathrm{BrJ}$ Psychiatry. 1987;150:407. [PubMed:3664117].

8. Wan SP, Soderdahl DW, Blight EJ. Nonpsychotic genital selfmutilation. Urology. 1985;26(3):286-7. [PubMed: 4035844].

9. Kaplan HI, Sadock BJ. Synopsis of psychiatry. 8th ed. New York: Courtney Milet; 1998. pp. 869-70.

10. Krauthammer C, Klerman GL. Secondary mania: manic syndromes associated with antecedent physical illness or drugs. Arch Gen Psychiatry. 1978;35(11):1333-9. [PubMed: 757997].

11. Vafaei B. Two case reports of self-mutilation or van Gogh syndrome. Acta Medica Iranica. 2003;41(3):199-201. 